\title{
O PROCESSO E OS ESTILOS DE APRENDIZAGEM DE GESTORES DE DIFERENTES FORMAÇÕES: ADMINISTRADORES E NÃO ADMINISTRADORES
}

\section{THE PROCESS AND THE STYLE OF LEARNING FOR MANAGERS OF DIFFERENT UNDERGRADUATE PROGRAMS: ADMINISTRATORS AND NOT ADMINISTRATORS}

\section{Camila Ribas de Souza}

Bacharel em Administração pela Universidade Presbiteriana Mackenzie.

E-mail: camis.ribas@gmail.com (Brasil)

\section{Juliana Oliveira Tanaka}

Bacharel em Administração pela Universidade Presbiteriana Mackenzie

E-mail: juliana.tanaka@gmail.com (Brasil)

\section{Maitê Fumagali Dias}

Bacharel em Administração pela Universidade Presbiteriana Mackenzie E-mail: maitefumagali@hotmail.com (Brasil)

\section{Natacha Bertoia da Silva}

Doutora em Administração pela Faculdade de Economia, Administração e Contabilidade da Universidade de São Paulo - FEA/USP.

Professora de Administração da Universidade Presbiteriana Mackenzie.

E-mail: natacha@mackenzie.br (Brasil) 


\title{
O PROCESSO E OS ESTILOS DE APRENDIZAGEM DE GESTORES DE DIFERENTES FORMAÇÕES: ADMINISTRADORES E NÃO ADMINISTRADORES
}

\section{RESUMO}

Este estudo visa analisar o processo de aprendizagem de gerentes e identificar possíveis diferenças entre gestores com distintas formações (administradores versus não administradores). Para tanto, foi desenvolvida uma pesquisa de caráter quantitativo, utilizando-se de uma amostra não probabilística composta por 72 gestores de diversas empresas situadas no estado de São Paulo. Os dados foram tratados com estatística descritiva, correlação, Anova e técnica de cálculo de estilos de aprendizagem de Kolb (1984). Os resultados mostram que o estilo de aprendizagem por acomodação é predominante para o total de gestores da amostra, o que é justificado pela existência de correlação entre o relacionamento interpessoal e a experiência dos indivíduos, além da aprendizagem informal que sobressaiu em ambos os grupos. Como uma das contribuições do estudo, a relação entre a aprendizagem, experiência e o relacionamento foram os principais indicativos de que o gestor apresenta mais interesse no aprendizado quando se relaciona com outras pessoas. O contato com outras pessoas permite ao gestor uma experiência prática ou vivência de determinado conhecimento, gerando, por fim, a percepção de uma aprendizagem mais efetiva. Isso corrobora com a preferência apresentada pelos gestores em processos informais de aprendizagem, aumentando a relevância das relações interpessoais.

Palavras-chave: Aprendizagem; Estilos de Aprendizagem; Aprendizagem Formal e Informal.

\section{THE PROCESS AND THE STYLE OF LEARNING FOR MANAGERS OF DIFFERENT UNDERGRADUATE PROGRAMS: ADMINISTRATORS AND NOT ADMINISTRATORS}

\begin{abstract}
This article aims to analyze the learning process of managers and identify possible differences between managers with different background (administrators versus non administrators). Therefore, a quantitative research was developed, using a non-probability sample composed by 72 managers of several companies located in the state of São Paulo. The data were treated with descriptive statistics, correlation, Anova and the calculation technique of learning styles developed by Kolb. The results show that the learning style for accommodation is predominant for the total managers of the sample, which is justified by the existence of correlation between the interpersonal relationship and the experience of individuals, in addition to the informal learning that emerged in both groups. As one of the contributions of the study, the relation between learning, experience and relationship were the main indications that the manager has more interest in learning when he relates to other people. The contact with other people provides the manager a practical experience or experience of a particular knowledge, generating as a result, the perception of a more effective learning. This corroborates the preference of managers for informal learning process, increasing the relevance of interpersonal relations.
\end{abstract}

Keywords: Learning; Learning Styles; Formal and Informal Learning.

Revista de Gestão e Secretariado - GeSec, São Paulo, v. 5, n. 2, p 72-96, mai./ago. 2014. 


\section{INTRODUÇÃO}

Algumas perspectivas (Kim, 1996; Antonello, 2011) apresentam a aprendizagem como um processo contínuo que se estende ao longo da vida. Absorver os conhecimentos do meio em que está inserido, transformá-los, e rever a si mesmo por meio de experiências, faz parte do ciclo de evolução da aprendizagem individual (Ruas, Antonello \& Boff, 2006). Aquele que tem como função gerenciar as relações humanas e operacionais possui um papel fundamental nos últimos anos, deixando de ser "aquele que manda" para ser aquele que promove a mudança em sua organização e auxilia seus subordinados a agirem com maior resiliência a elas (Leite, Godoy \& Antonello, 2003). Logo, emerge um novo perfil de gerente, motivando maiores investimentos na aprendizagem destes profissionais, a fim de que se possa associar fielmente o planejamento estratégico coorporativo às ações executadas no cotidiano da organização (Fleury \& Fleury, 2001).

Concomitantemente, a demanda por estudos da aprendizagem gerencial vem crescendo e recebendo ao longo do tempo contribuições de diferentes áreas do conhecimento, inclusive da área da administração.

Para diversos autores existe certa distinção entre o processo de aprendizagem gerencial que ocorre no indivíduo, e as respostas emitidas por ele, as quais podem ser visíveis e mensuráveis. Para Moraes, Silva \& Cunha (2004), a aprendizagem gerencial não pode ser vista apenas como o resultado da transferência do conhecimento em situações planejadas, mas também como um processo contínuo que ocorre durante toda a trajetória profissional, proveniente e dependente de um contexto social específico. Dessa maneira, a interação social é a base para o processo de aprendizagem gerencial, o que reforça a posição de Antonello (2005) de que os dois tipos de aprendizagem, formal e informal, estarão sempre se inter-relacionando e seu equilíbrio varia expressivamente de situação para situação, sendo vinculados diretamente ao contexto organizacional, social e cultural do ambiente onde a aprendizagem ocorre.

$\mathrm{O}$ crescente interesse em pesquisas e práticas sobre a aprendizagem gerencial tem como origem o ceticismo dos pesquisadores em relação à efetividade dos programas de educação e desenvolvimento gerencial (Moraes, Silva \& Cunha, 2004). Segundo Moraes, Silva \& Cunha (2004), os pesquisadores deveriam investigar como os gerentes aprendem, com o intuito de diminuir a lacuna entre a teoria e a aplicação prática da gama de conhecimentos. Nota-se que embora haja um material teórico abrangente sobre o assunto, os estudos empíricos sobre a aprendizagem gerencial ofereceram um vasto campo de pesquisa, o que justifica o presente estudo.

Considerando que nem todo gestor tem formação acadêmica, ou aprendizagem formal, em

Revista de Gestão e Secretariado - GeSec, São Paulo, v. 5, n. 2, p 72-96, mai./ago. 2014. 
administração, é possível que formas de aprendizagem informal sejam relevantes para a atuação no contexto organizacional. Neste estudo analisamos o processo de aprendizagem de gerentes para identificar possíveis diferenças entre gestores com diferentes formações (administradores versus não administradores). Ao longo do desenvolvimento da pesquisa, buscou-se também: compreender o estilo de aprendizagem dos gestores, identificar as variáveis contextuais que influenciam nessa aprendizagem e compreender o processo de aprendizagem formal e informal dos gestores de diferentes formações. Metodologicamente, realizou-se um estudo quantitativo descrito, sendo a coleta de dados eletrônica, por meio de um questionário composto de quatro partes complementares: questões demográficas, inventário do estilo de aprendizagem de Kolb, afirmativas referentes às variáveis contextuais e, afirmativas que abordavam aspectos da aprendizagem formal e informal. A amostra foi não probabilística, representando um total de 72 respostas válidas. Para análise dos dados, utilizou-se estatística descritiva, correlação e Anova.

Como um dos resultados do estudo, a relação entre a aprendizagem, experiência e o relacionamento foram os principais indicativos de que o gestor apresenta mais interesse no aprendizado quando se relaciona com outras pessoas que o leva a uma experiência prática daquele conhecimento, gerando por fim a percepção de maior aprendizagem. O que corrobora com a preferência apresentada pelos gestores em processos informais de aprendizagem, aumentando a relevância das relações interpessoais.

$\mathrm{O}$ artigo está estruturado em cinco partes. Primeiro, o referencial teórico contempla os diversos conceitos de aprendizagem individual, os processos nos quais a aprendizagem se apresenta - formal e informal - e seus níveis - individual grupal e organizacional. Em seguida, detalhamos os aspectos metodológicos do estudo. Na terceira parte, expõem-se os resultados. Por fim, as considerações finais.

\section{REFERENCIAL TEÓRICO}

\subsection{APRENDIZAGEM INDIVIDUAL}

Para alguns autores existe certa distinção entre o processo de aprendizagem que ocorre no organismo de quem aprende e as respostas emitidas pelo indivíduo, as quais podem ser visíveis e

Revista de Gestão e Secretariado - GeSec, São Paulo, v. 5, n. 2, p 72-96, mai./ago. 2014. 
mensuráveis. Sendo assim, os modelos de aprendizagem se sustentam basicamente em duas vertentes teóricas: comportamental e cognitivo. A comportamental tem como foco o comportamento que pode ser observado e mensurado. Neste caso, planeja-se o processo de aprendizagem através do condicionamento. O cognitivo enfoca aspectos comportamentais, objetivos e subjetivos, considerando crenças e percepção do indivíduo, que influenciam no processo de apreensão da realidade (Fleury \& Oliveira Jr., 2002). Segundo Dantas (2011), o "Inventário sobre os estilos de aprendizagem de Kolb" é o instrumento adequado para identificar o estilo de aprendizagem predominante e seu estágio, além de ter a melhor aplicação, por meio dos resultados obtidos, pode-se concluir a forma de preferência de aprendizagem do indivíduo.

A teoria de Kolb (1984) aborda quatro distintos estilos de aprendizagem - Divergência, assimilação, convergência e acomodação (ver Figura 1) -, em que cada um é representado pela combinação de dois estilos preferidos pelo indivíduo, ou seja, aqueles com os quais mais se identificam. Esses quatro estilos se baseiam em um círculo de aprendizagem experiencial subdivididos em quatros estágios: experiência concreta (sentir), observação reflexiva (observar), conceituação abstrata (pensar) e experimentação ativa (fazer). O círculo é dividido por dois eixos, relacionados dialeticamente, chamados de: contínuo de processamento (fazer ou observar) que se refere à experiência compreensiva de como o indivíduo aborda a tarefa; e, o contínuo de percepção (sentir ou pensar) que se refere à experiência transformadora fruto de uma resposta emocional à tarefa.

Figura 1- Matriz dos estilos de aprendizagem de Kolb

\begin{tabular}{|c|c|c|}
\hline & $\begin{array}{c}\text { Fazer } \\
\text { (Experimentação ativa) }\end{array}$ & $\begin{array}{c}\text { Observar } \\
\text { (Observação reflexiva) }\end{array}$ \\
\hline $\begin{array}{c}\text { Sentir } \\
\text { (Experiência concreta) }\end{array}$ & ACOMODAÇÃO & DIVERGÊNCIA \\
\hline $\begin{array}{c}\text { Pensar } \\
\text { (Conceituação abstrata }\end{array}$ & CONVERGÊNCIA & ASSIMILAÇÃO \\
\hline
\end{tabular}

Fonte: Adaptado de Kolb (1984)

O estilo divergência, que reúne o sentir e o observar, está relacionado a pessoas que possuem habilidades para observar as coisas de diferentes perspectivas. Indivíduos com este estilo preferem trabalhar em grupos que viabilizem alcançar diversas informações e tentem a usar a imaginação para resolver problemas (Kolb, 1984).

A assimilação é o estilo resultante da união do observar e pensar, propõe uma abordagem concisa e lógica em que ideias e conceitos são mais importantes do que pessoas. Pessoas com esse

Revista de Gestão e Secretariado - GeSec, São Paulo, v. 5, n. 2, p 72-96, mai./ago. 2014. 
estilo se atraem mais por teorias com embasamento lógico do que aquelas focadas em conceitos abstratos ou valores práticos. A eficiência na informação e o desenvolvimento em carreiras científicas são os principais resultados de pessoas adeptas a esse estilo (Kolb, 1984).

A união do fazer e do pensar resulta no estilo de convergência em que os indivíduos buscam resolver problemas e usam sua aprendizagem para encontrar soluções para questões práticas. Em geral preferem tarefas técnicas, menos relacionadas com aspectos interpessoais. Esse estilo favorece o desenvolvimento de habilidades especialistas e de tecnologia por meio da experimentação de novas ideias, simulações e aplicações práticas (Kolb, 1984).

Por fim o estilo que envolve fazer e sentir, a acomodação, faz uso da intuição mais do que da lógica. Comumente, indivíduos com esse estilo são atraídos por novos desafios e são mais produtivos quando atuam em posições que exijam ação e iniciativa. E por esta natureza, preferem usar a análise de outros indivíduos e trabalhar em ações coletivas (Kolb, 1984).

Antes, porém, para que tais estágios se percorram integralmente é preciso maturidade do indivíduo. Este desenvolvimento foi desmembrado em três categorias por Kolb (1984). São elas: aquisição que ocorre do nascimento à adolescência; especialização que acontece no momento da escolarização, primeiros trabalhos e experiências da idade adulta e Integração que se desenvolve ao longo da meia-idade até ao fim da vida. Há ainda a concepção de que aprender significa confrontar uma nova situação ou resolvê-la de outra maneira, significa que, na trajetória da interação da pessoa com o ambiente, em circunstâncias específicas, faz-se necessário comportar-se ou agir de maneira diferente do habitual (D’Amelio, 2007). Porém, para Godoy e Antonello (2009), a aprendizagem não deve ser compreendida apenas como obtenção de competências, pois é de extrema valia identificar os principais usos do conceito de aprendizagem dentro de uma organização para que ele possa ser efetivamente desenvolvido em benefício desta e de seus membros.

\subsection{APRENDIZAGEM FORMAL E INFORMAL}

Por haver intensa tendência em entender que aprendizagem formal e informal são apartadas, há autores na literatura que buscam denegrir a informal em relação à formal e vice-versa. É importante não levar em consideração que a aprendizagem formal ou informal são inerentes ou superiores uma a outra (Antonello, 2011). No que se refere ao conceito de aprendizagem formal,

Easterby-Smith, Burgoyne \& Araújo (2001) mencionam que a aprendizagem se assemelha a um

Revista de Gestão e Secretariado - GeSec, São Paulo, v. 5, n. 2, p 72-96, mai./ago. 2014. 
processo técnico que supõe se tratar de um mecanismo eficaz de interpretação e resposta a informações internas e externas a organização. Já Antonello (2011) argumenta que o importante é descobrir a interação entre a aprendizagem formal e informal. Para a autora, trata-se de uma atividade única, porém em duas dimensões: aprendizagem formal é aquela que ocorre individualmente dentro do estabelecimento de ensino e, aprendizagem informal ocorre por práticas presentes no cotidiano dos espaços educacionais.

Tanto a aprendizagem informal quanto a aprendizagem formal são essenciais e devem ser utilizadas conforme a demanda da organização pelo fato de ressaltarem a necessidade de melhoria contínua do desempenho dos indivíduos. A aprendizagem formal é importante para atender as necessidades dos trabalhadores e é embasada nas habilidades e nos conhecimentos que são transmitidos. Aprender formalmente pode proporcionar habilidades e/ou conhecimentos específicos; espera-se que, após o treinamento, o indivíduo se torne apto a desempenhá-los na rotina de trabalho. É caracterizada por métodos, técnicas, locais e condições particulares criadas com o intuito de gerar ideias, conhecimentos, valores, atitudes e comportamentos. Já a aprendizagem informal, incide de maneira natural ou não planejada no trabalho, é pautada na espontaneidade e tem diversas fontes como: tentativa e erro, imitação, autodidatismo e busca de ajuda interpessoal. Pode proporcionar resultados positivos, pelo fato de sua aplicabilidade e transferência ter efeito instantâneo para o indivíduo (Coelho \& Borges-Andrade, 2008).

Antonello (2005) destaca que a aprendizagem formal e a informal estarão sempre interrelacionadas, visto que há elementos expressivos de aprendizagem formal em situações informais, assim como o contrário. Logo, as situações de aprendizagem possuem características de formalidade e de informalidade, em que o equilíbrio entre elas varia expressivamente de situação para situação e está vinculado diretamente ao contexto organizacional, social, cultural, onde a aprendizagem acontece.

\subsection{APRENDIZAGEM GERENCIAL}

Um dos conceitos que mais tem influenciado a teoria e prática da aprendizagem gerencial concebe a aprendizagem de adultos como um processo autodirecionado, em que o indivíduo é responsável por sua aprendizagem, que pode ocorrer sem a ajuda de um facilitador. O que o conceito busca demonstrar é que cabe ao indivíduo escolher os diferentes caminhos para atingir diversos objetivos de aprendizagem. A aprendizagem de adultos pode ocorrer em duas modalidades: formal, como cursos de especialização e seminários, e informal, como a leitura de

Revista de Gestão e Secretariado - GeSec, São Paulo, v. 5, n. 2, p 72-96, mai./ago. 2014. 
livros, revistas e a consulta a especialistas. Dessa forma, os gerentes autodirecionam sua aprendizagem de modo a absorver conteúdos que o levem a encarar melhor as mudanças que fazem parte de sua vida diária, rompendo com a visão tradicional de que a aprendizagem é apenas uma transferência de conhecimento, mas sim um processo complexo e dinâmico, que ocorre ao longo da trajetória profissional dos executivos (Moraes, Silva \& Cunha, 2004). Seguindo essa lógica, Leite (2011) apresenta as habilidades necessárias aos gerentes, que podem ser aprendidas antes ou durante o gerenciamento, por meio da experiência vivenciada pelo cotidiano desta função, sendo elas analisadas por três aspectos: habilidades técnicas, habilidades com subordinados e habilidades comportamentais.

O que se observa nas habilidades técnicas, é que estão ligadas a uma visão mais estratégica e são aprendidas pela experiência. Embora a gestão de pessoas seja reconhecida como necessária aos gerentes, aprender a gerenciar envolve um aprendizado cotidiano, constante que se realiza a partir da interação entre gerentes e subordinados, e, por isso tanto as habilidades aprendidas antes e durante o gerenciamento quanto às habilidades aprendidas com maior dificuldade, devem ser levadas em consideração. Já em relação às habilidades comportamentais, observa-se que elas são intrínsecas às características pessoais e menos relacionadas com as ações (Leite, 2011).A aprendizagem de gerentes integra o estudo da educação, da experiência vivenciada e o contexto da ação gerencial. Suas bases conceituais envolvem psicologia, educação, sociologia e teoria das organizações com maior foco na relação entre a educação, o desenvolvimento e a prática gerencial. A aprendizagem é um processo multifacetado que está sujeito a uma série de variáveis contextuais, econômicas, culturais, tecnológicas as quais estão interligadas e que influenciam o modo como os indivíduos em geral veem o mundo e atribuem significados a determinados acontecimentos. Além disso, no contexto da aprendizagem gerencial em especifico, há uma série de aspectos que fomentam a aprendizagem, assim como o relacionamento entre pares, superiores e subordinados, a leitura de normas e procedimentos, a troca de experiências, entre outros, conforme segue na Tabela 1 (Silva, 2008).

Revista de Gestão e Secretariado - GeSec, São Paulo, v. 5, n. 2, p 72-96, mai./ago. 2014. 
Tabela 1 - Variáveis contextuais

\begin{tabular}{|c|l|}
\hline $\begin{array}{c}\text { VARIÁVEIS } \\
\text { CONTEXTUAIS }\end{array}$ & \multicolumn{1}{c|}{ DESCRIÇÃo } \\
\hline Econômicos & $\begin{array}{l}\text { A velocidade da mudança econômica gera a necessidade da aprendizagem. Os } \\
\text { mercados buscam competitividade. }\end{array}$ \\
\hline Tecnológicos & $\begin{array}{l}\text { O conhecimento, as ferramentas, as técnicas e as atividades que transformam inputs em } \\
\text { resultados. Com as transformações do ambiente, as tecnologias se tornam obsoletas } \\
\text { rapidamente, o que influencia a aprendizagem. }\end{array}$ \\
\hline Culturais & $\begin{array}{l}\text { Ela é formada por um sistema de crenças, valores e atitudes que servem como } \\
\text { balizadores do comportamento humano. Interferem na aprendizagem na medida que os } \\
\text { indivíduos resistem as mudanças ou até mesmo a abandonar seus modelos mentais. Os } \\
\text { modelos mentais são pressupostos que fomentam nossa forma de ver o mundo. }\end{array}$ \\
\hline Experiências & $\begin{array}{l}\text { Ao avaliar sua trajetória profissional, um gerente percebe que as situações mais } \\
\text { significativas e ricas em aprendizagem foram aquelas em que houve a troca de } \\
\text { experiências, em que os comportamentos vivenciados o levaram a ter sensações que } \\
\text { hoje servem de base para as suas ações. }\end{array}$ \\
\hline Relacionamento & $\begin{array}{l}\text { Para que ocorra a aprendizagem no ambiente de trabalho é fundamental que exista uma } \\
\text { troca entre os indivíduos, a aprendizagem é uma função da interação entre as pessoas, } \\
\text { ambiente e comportamento. }\end{array}$ \\
\hline Normas e & $\begin{array}{l}\text { Abrange um sistema de valores que auxilia os indivíduos a entenderem situações } \\
\text { práticas, auxiliando na formulação de objetivos e diretrizes para a ação, determinando } \\
\text { o que estabelece uma conduta social aceitável. }\end{array}$ \\
\hline
\end{tabular}

Fonte: Adaptado de Silva (2008)

Desta mesma forma, o processo de aprendizagem de gerentes é multidimensional, pois abrange duas dimensões: a objetiva e a subjetiva da prática gerencial. Segundo D’Amelio (2011), as capacidades gerenciais que moldam a gestão, mostram-se influenciadas pelas experiências obtidas na carreira profissional, guardando semelhanças entre os grupos. As experiências profissionais correspondem às bases que alimentam o desenvolvimento das capacidades gerenciais. Um estudo realizado pela autora evidenciou que as experiências de aprendizagem adquiridas pelos gerentes com diferentes formações, fruto das interações sociais, auxiliam na reflexão destes profissionais sobre o papel expressivo que desempenham nas organizações, além de potencializar a aprendizagem de outras competências. Assim, observa-se que é imprescindível para as organizações a existência de profissionais dispostos a "aprender a aprender", além de compartilhar o que foi aprendido com outras pessoas da organização, resultando em um ambiente organizacional favorável ao aprendizado e permitindo que as organizações tenham diferentes posicionamentos estratégicos em diversos momentos de sua trajetória (Estivalete, Lobler \& Pedrozo, 2006). 


\section{MÉTODO}

Tendo em vista o objetivo do estudo "analisar o processo de aprendizagem de gerentes para identificar possíveis diferenças entre gestores com diferentes formações (administradores versus não administradores)", utilizou-se o método quantitativo descritivo, com recorte transversal. Para Sampieri, Collado \& Lucio (2006), o método quantitativo tem como objetivo quantificar e destacar uma teoria existente para esclarecer algo, e é utilizado para proporcionar respostas ao problema de pesquisa a partir de questionários ou estudos em que instrumentos padronizados de serem medidos são utilizados. No caso do tipo de pesquisa, o estudo descritivo trata de um tipo de pesquisa estruturado, que tem como objetivo a descrição de algo e a determinação do grau de associação entre as variáveis pesquisada (Malhotra, 2011). Ao serem definidos com transversais, os "estudos descritivos podem dar ao usuário um panorama ou uma descrição dos elementos administrativos em um dado ponto do tempo", enquanto os longitudinais descrevem os eventos ao longo do tempo (Hair, 2005, p. 85).

\subsection{TÉCNICA E INSTRUMENTO DE COLETA DE DADOS}

A técnica de coleta escolhida para o estudo foi um questionário eletrônico, disponível em um site da Internet. De acordo com Babbie (2005), esta técnica envolve a coleta e a quantificação dos dados, e permite não apenas descrever a amostra selecionada, mas também descrever subamostras e compará-las. O questionário conteve três partes. A primeira, com objetivo identificar a existência de algum estilo de aprendizagem no processo de aprendizagem dos gerentes, utilizou o "Inventário de estilos de aprendizagem" (Kolb, 1984), validado em estudos anteriores, que define quatro estilos de aprendizagem: acomodador, divergente, assimilador e convergente, sendo ele composto de 12 perguntas. A segunda e a terceira parte visaram identificar as variáveis contextuais que influenciam na aprendizagem e a existência de aprendizagem formal e ou informal. Nestas duas partes, constituídas por 34 afirmativas a serem avaliadas pelos respondentes por meio de uma escala tipo Likert de cinco pontos (variando de 1, discordo totalmente, a 5, concordo totalmente).

Para verificar as variáveis contextuais (Tabela 2), 17 afirmativas foram elaboradas a partir do estudo de Leite (2013), com o objetivo de identificar as percepções dos gestores quanto a: relacionamento com pares, superiores e subordinados, leitura de normas, procedimentos,

Revista de Gestão e Secretariado - GeSec, São Paulo, v. 5, n. 2, p 72-96, mai./ago. 2014. 
sistemas de informações gerenciais, fatores demográficos, econômicos, tecnológicos, culturais e experiências vividas.

Tabela 2 - Afirmativas referentes às variáveis contextuais

\begin{tabular}{|c|c|}
\hline VARIÁVEL & AFIRMATIVA \\
\hline \multirow{5}{*}{ Cultura } & Tenho oportunidades para aprender e crescer no trabalho. \\
\hline & Sinto-me estimulado a buscar novos conhecimentos fora da empresa. \\
\hline & Recebo apoio e incentivo da empresa para aplicar novos conhecimentos. \\
\hline & $\begin{array}{l}\text { Os valores básicos da organização onde trabalho incluem a aprendizagem como a chave para a } \\
\text { melhoria. }\end{array}$ \\
\hline & Preocupo-me com o respeito à diversidade e questões sociais. \\
\hline \multirow{3}{*}{ Experiência } & Acredito que seja importante aprender com cada uma de minhas experiências no trabalho. \\
\hline & Aprendo quando realizo reflexão sobre as atitudes do meu dia a dia. \\
\hline & Tenho facilidade para adquirir conhecimento a partir de uma vasta gama de informações. \\
\hline \multirow{4}{*}{ Relacionamento } & Ter autonomia favorece minha aprendizagem. \\
\hline & Aprendo no trabalho, com a troca de experiências e ideias entre os colaboradores. \\
\hline & $\begin{array}{l}\text { Convidamos pessoas de fora da nossa equipe para apresentar informações ou debater conosco } \\
\text { assuntos de interesse. }\end{array}$ \\
\hline & Sinto-me motivado quando recebo reconhecimento pelo trabalho que desenvolvo. \\
\hline \multirow{2}{*}{$\begin{array}{l}\text { Normas e } \\
\text { procedimentos }\end{array}$} & $\begin{array}{l}\text { Tenho consciência do papel que desempenho no meu trabalho e procuro defender minha } \\
\text { opinião. }\end{array}$ \\
\hline & $\begin{array}{l}\text { Sou conservador e respeito as posições hierárquicas, as tradições, as leis e as regras diversas } \\
\text { existentes na minha empresa. }\end{array}$ \\
\hline $\begin{array}{c}\text { Econômico } \\
\text { cultural e valores }\end{array}$ & Valorizo o equilíbrio entre minha vida pessoal e profissional. \\
\hline Econômico & $\begin{array}{l}\text { Sinto vontade de permanecer no meu trabalho se vislumbro oportunidades de crescimento na } \\
\text { carreira e quando recebo incentivos monetários. }\end{array}$ \\
\hline Tecnológico & Valorizo a criatividade e a inovação. \\
\hline
\end{tabular}

Fonte: Elaborado a partir de Leite (2013).

As outras 17 perguntas foram direcionadas à identificação da preferência dos gestores na aprendizagem informal ou formal, a partir da adaptação dos questionários validados dos estudos de Bido, Godoy, Ferreira, Kenski e Scartezini (2011), a saber:

- aprendo melhor em cursos presenciais quando comparado aos cursos a distância;

- prefiro aprender por meio de atividades independentes, que possam ser realizadas individualmente e no meu próprio ritmo, ao invés do trabalho em equipe;

Revista de Gestão e Secretariado - GeSec, São Paulo, v. 5, n. 2, p 72-96, mai./ago. 2014. 
- aprendo em treinamentos, tanto presenciais quanto a distância;

- o trabalho me estimula a buscar novos conhecimentos dentro da empresa;

- considero que novos conhecimentos contribuirão para o meu desenvolvimento;

- busco ajuda de colegas para esclarecer uma dúvida;

- prefiro aprender por meio de recursos tecnológicos e meios de comunicação, como ensino a distância e treinamentos online;

- $\quad$ sinto-me seguro em compartilhar o que já sei;

- reuniões favorecem a aprendizagem;

- aprendo quando leio ou assisto a um vídeo;

- aprendo quando faço coisas;

- após o treinamento presencial, aplico o conhecimento adquirido em meu dia a dia;

- após interação com pares, aplico o conhecimento adquirido em meu dia a dia;

- aprendo melhor em cursos a distância quando comparado aos cursos presenciais;

- estou sempre aprendendo algo novo em meu trabalho;

- tenho maior interesse por atividades participativas, que envolvam investigação, observação e experimentação;

- prefiro aprender através dos meios convencionais, como palestras e atividades presenciais, que envolvam menor uso de novas tecnologias.

O questionário foi sujeito a um pré-teste com o objetivo de avaliar a clareza das questões e evitar duplo sentido, verificando se os enunciados das questões possuíam fácil entendimento e qual o tempo médio que os respondentes levariam para concluir o questionário.

\subsection{CARACTERIZAÇÃO DA AMOSTRA}

O método de amostragem escolhido foi o não probabilístico e por conveniência, pois não é estatisticamente representativa da população-alvo, não sendo, portanto, possível a generalização dos resultados (Hair, 2005). Com relação às técnicas de amostragem escolhidas, a por conveniência promove a escolha dos elementos por meio da disponibilidade deles e da coincidência de estarem no lugar e momento certos e poderem fornecer a informação necessária (Hair, 2005; Malhotra, 2011).

Revista de Gestão e Secretariado - GeSec, São Paulo, v. 5, n. 2, p 72-96, mai./ago. 2014. 
Sendo assim, foram considerados como elementos da base de respondentes gerais todos os profissionais que responderam ao questionário online, que atuam em diferentes empresas privadas no estado de São Paulo, que possuíam algum contato com as pesquisadoras, sem restrição ao nível hierárquico que ocupavam em abril de 2013.

O estudo foi composto por um total de 104 respondentes, mas após a coleta dos dados, foi feita a exclusão de 32 respondentes com dados incompletos, que não finalizaram a pesquisa ou que não se enquadravam ao perfil da amostra. Assim, considerando o recorte de nível hierárquico contendo apenas gestores, supervisores e diretores de empresas privadas, o total da amostra considerado para as análises no presente estudo foi de 72 respondentes. Dentre esses respondentes, foram identificadas diversas formações superiores, como demonstrados na Tabela 3.

Tabela 3 - Graduação dos respondentes

\begin{tabular}{|l|c|}
\hline Administração & 26 \\
\hline Engenharia & 10 \\
\hline Economia & 6 \\
\hline Direito & 4 \\
\hline Comércio Exterior & 3 \\
\hline Sistemas de Informação & 3 \\
\hline Contabilidade & 1 \\
\hline Jornalismo/Comunicação & 1 \\
\hline Propaganda, Publicidade e Criação & 1 \\
\hline Outros & 17 \\
\hline Total & 72 \\
\hline
\end{tabular}

Em relação à formação acadêmica dos gestores, o percentual das respostas distribuiu-se em $36 \%$ administração, $25 \%$ outros cursos (que incluem psicologia, farmácia, matemática e ciência da computação), $14 \%$ engenharia, $8 \%$ economia, $6 \%$ direito, $4 \%$ comércio exterior e sistemas de informação, $1 \%$ contabilidade, jornalismo/comunicação e propaganda, publicidade e criação. Com a finalidade de fazer análise estatística e comparativa, foram considerados como administradores os profissionais com formação superior em administração de empresas, contabilidade, economia e comércio exterior, compondo assim $50 \%$ do total da amostra. Para fazer a comparação do processo de aprendizagem e identificar possíveis diferenças entre gestores com distintas formações, foram considerados como "não administradores" os profissionais com as demais formações superiores.

Em relação à idade, a maioria dos respondentes (52\%) possuía entre 35 a 44 anos, e $32 \%$ entre 25 e 34 anos, $15 \%$ entre 45 a 54 anos e 1\% entre 18 a 24 anos. Em relação ao sexo, a amostra exibiu um extrato de maioria masculino com $61 \%$ versus $39 \%$ feminino.

Revista de Gestão e Secretariado - GeSec, São Paulo, v. 5, n. 2, p 72-96, mai./ago. 2014. 
Em relação aos cargos, os respondentes concentraram-se em um percentual de $53 \%$ de gerentes, seguido de 39\% de supervisão ou coordenação e $8 \%$ superintendência de ou diretoria, sendo que $35 \%$ encontram-se neste cargo entre dois a quatro anos contra $22 \%$ que estão neste cargo há menos de dois anos.

\subsection{PROCEDIMENTOS DE ANÁLISE DOS DADOS}

Depois de realizada a coleta de dados, foi feito um recorte por julgamento na base de respondentes geral, onde foram selecionados apenas os dados dos respondentes com cargo de coordenação ou superior, o que resultou num número total de 72 gestores para a amostra, enquanto que o número total de respondentes foi de 104.

A partir da tabulação das respostas em uma base única de dados no MS Excel, foram realizadas diversas análises descritivas, como percentuais de cada um dos cursos de formação na amostra, percentuais de gênero e idade; e análises estatísticas, tais como correlação e Anova. No caso das correlações, foram realizadas comparações entre as respostas dos profissionais no geral, entre as respostas dos gestores com formação em administração e outras formações, e entre gestores divididos por gênero. No caso da Anova, foram realizados testes para identificar diferenças entre gestores formados em administração e outros cursos para cada uma as variáveis contextuais.

\section{RESULTADOS}

Esta seção, dividida em três partes, aborda inicialmente a síntese dos estilos de aprendizagem de Kolb dos respondentes, seguido pelos resultados obtidos sobre o processo de aprendizagem formal e informal da amostra e, é finalizada com as variáveis contextuais que influenciam a aprendizagem dos gestores.

\subsection{ESTILOS DE APRENDIZAGEM DOS PROFISSIONAIS DE NEGÓCIOS (KOLB)}

Para identificar os estilos de aprendizagem, a primeira parte do questionário foi composta pelo "Inventário sobre os estilos de aprendizagem" (IEA) de Kolb, que oferece uma maneira de

Revista de Gestão e Secretariado - GeSec, São Paulo, v. 5, n. 2, p 72-96, mai./ago. 2014. 
compreender os estilos de aprendizagem individual dos gestores. Na Tabela 4 são apresentados os "índices de aprendizagem de Kolb", que revelaram que a maioria dos entrevistados (35\%) possui como predominante o índice de Observação Reflexiva (OR), que de acordo com Dantas (2011), o indivíduo com este perfil tende a ser cauteloso para não fazer julgamentos precipitados e, portanto, procura ser imparcial ao ato de aprender. Indica que estes gestores, em ambos os grupos, têm maior preferência pela abordagem de tentativa e erro a partir de uma cuidadosa observação, tendem a buscar aprender por meio de aulas e vídeos, onde possam realizar julgamentos imparciais sobre o conteúdo abordado.

Observa-se que para os gestores de modo geral o segundo maior índice (26\%) foi o de conceituação abstrata, que, segundo Dantas (2011) indica a preferência por um modo de aprendizagem analítico, impessoal e lógico. De acordo com Kolb (1984) a conceituação abstrata é o processo que envolve interpretação dos eventos e compreender a relação entre eles. Conforme a Tabela 4, os gestores não administradores também possuem esse índice em destaque, representando $36 \%$ do total desses profissionais. No caso dos gestores formados em administração, o segundo maior índice foi o de experimentação ativa, com $28 \%$, o que indica que estes profissionais possuem uma forte disposição a realizar atividades práticas que envolvem projetos e discussões em grupo (Dantas, 2011). O indivíduo coloca em prática o que aprende e converte em ações futuras, que são utilizadas em determinadas situações na tomada de decisão (Kolb, 1984).

Tabela 4 - Distribuição dos índices de aprendizagem dos gestores

\begin{tabular}{|l|c|c|c|c|c|c|}
\hline \multicolumn{1}{|c|}{ ÍNDICE } & GERAL & $\%$ & ADMINISTRADORES & $\%$ & ADMINISTRADORES & NÃO \\
\hline Experiência Concreta & 6 & $8 \%$ & 5 & $14 \%$ & 1 & $3 \%$ \\
\hline Observação Reflexiva & 25 & $35 \%$ & 12 & $33 \%$ & 13 & $36 \%$ \\
\hline Conceituação Abstrata & 19 & $26 \%$ & 6 & $17 \%$ & 13 & $36 \%$ \\
\hline Experimentação Ativa & 18 & $25 \%$ & 10 & $28 \%$ & 8 & $22 \%$ \\
\hline Dois ou mais perfis & 4 & $6 \%$ & 3 & $8 \%$ & 1 & $3 \%$ \\
\hline Total & 72 & $100 \%$ & 36 & $100 \%$ & 36 & $100 \%$ \\
\hline
\end{tabular}

Fonte: elaborado pelos autores com dados da pesquisa.

Percebe-se, também, que entre os administradores há maior influência da experimentação ativa, estágio em que a realização de atividades práticas é o principal embasamento do estilo de aprendizagem, enquanto que para os não administradores há influência da conceituação abstrata que remete a um modo de aprendizagem mais analítico e com maior peso no raciocínio lógico, além de ser mais orientado a símbolos do que a pessoas (Dantas, 2011).

Revista de Gestão e Secretariado - GeSec, São Paulo, v. 5, n. 2, p 72-96, mai./ago. 2014. 
A Tabela 5 apresenta os resultados dos "Estilos de aprendizagem de Kolb". Tais resultados são originados dos cálculos indicados no "Inventário sobre os estilos de aprendizagem" (IEA) de Kolb (1984), que foram realizados individualmente, para cada um dos 72 gestores e, posteriormente, analisados nos grupos de comparação (administradores e não administradores).

Observa-se na Tabela 5 a predominância do estilo de aprendizagem pela acomodação, com $35 \%$ do geral dos respondentes, 33\% dos administradores e 36\% dos não administradores. Isso indica que os profissionais têm como preferência a experiência como fonte de aprendizagem, adaptam-se a circunstâncias imediatas e aceitam facilmente novos desafios (Dantas, 2011). O gestor que possui este estilo de aprendizagem baseia-se na intuição ao invés de lógica e tende a depender dos outros para obter informações (Kolb, 1984). O estilo de aprendizagem por divergência também se destaca, com 31\% dos gestores geral, 25\% dos administradores e 36\% dos não administradores. Os profissionais que possuem esse estilo de aprendizagem têm a habilidade de lidar com diversos pontos de vista e inter-relacioná-los entre si (Dantas, 2011). Kolb (1984) denomina divergentes as pessoas que têm o melhor desempenho em situações que exigem gerações de ideias, e informa que os indivíduos com este estilo de aprendizagem têm amplos interesses culturais, coletam informações e utilizam a imaginação para resolver problemas.

Tabela 5 - Distribuição dos estilos de aprendizagem dos gestores

\begin{tabular}{|l|c|c|c|c|c|c|}
\hline \multicolumn{1}{|c|}{ ESTILO } & GERAL & $\boldsymbol{*}$ & ADMINISTRADORES & $\boldsymbol{\%}$ & $\begin{array}{c}\text { NÃO } \\
\text { ADMINISTRADORES }\end{array}$ & $\boldsymbol{\%}$ \\
\hline Acomodação & 25 & $35 \%$ & 12 & $33 \%$ & 13 & $36 \%$ \\
\hline Assimilação & 11 & $15 \%$ & 6 & $17 \%$ & 5 & $14 \%$ \\
\hline Convergência & 10 & $14 \%$ & 5 & $14 \%$ & 5 & $14 \%$ \\
\hline Divergência & 22 & $31 \%$ & 9 & $25 \%$ & 13 & $36 \%$ \\
\hline Dois ou mais estilos & 4 & $6 \%$ & 4 & $11 \%$ & 0 & $0 \%$ \\
\hline Total & 72 & $100 \%$ & 36 & $100 \%$ & 36 & $100 \%$ \\
\hline
\end{tabular}

Fonte - elaborado pelos autores com dados da pesquisa.

\subsection{APRENDIZAGEM FORMAL E INFORMAL}

De acordo com a Tabela 6, com as porcentagens de concordância para aprendizagem formal

e informal, observou-se que $83 \%$ dos administradores (em contraste com $69 \%$ dos não

Revista de Gestão e Secretariado - GeSec, São Paulo, v. 5, n. 2, p 72-96, mai./ago. 2014. 
administradores) afirmaram aprender melhor em cursos presenciais do que em cursos a distância. Com relação à afirmativa de que a atual atividade profissional exercida estimula os respondentes a buscar novos conhecimentos dentro da empresa, $81 \%$ administradores e $94 \%$ dos não administradores concordaram. Considerando essas duas afirmativas, foi possível identificar a relação delas com a aprendizagem autodirecionada (Moraes, Silva \& Cunha, 2004), em que o profissional assume as responsabilidades pela sua trajetória de desenvolvimento sem a necessidade de intervenção de outros indivíduos. As respostas indicaram que aqueles que têm formação em administração demonstram ter menos autonomia ao ato de aprender do que os que possuem outras formações. Os não administradores, portanto, posicionaram-se como menos dependentes de intervenções de outras pessoas no processo de aprendizagem.

Tabela 6 - Concordância para perguntas sobre aprendizagem formal e informal

\begin{tabular}{|c|c|c|c|c|}
\hline $\begin{array}{c}\text { TIPO DE } \\
\text { APRENDIZAGEM }\end{array}$ & PERGUNTA & GERAL & ADMINISTRADORES & $\begin{array}{c}\text { NÃO } \\
\text { ADMINISTRADORES }\end{array}$ \\
\hline $\begin{array}{l}\text { FORMAL E } \\
\text { INFORMAL }\end{array}$ & $\begin{array}{l}\text { Considero que novos conhecimentos } \\
\text { contribuirão para o meu } \\
\text { desenvolvimento }\end{array}$ & $97 \%$ & $94 \%$ & $100 \%$ \\
\hline \multirow{8}{*}{ FORMAL } & $\begin{array}{l}\text { Aprendo melhor em cursos } \\
\text { presenciais quando comparado aos } \\
\text { cursos a distância }\end{array}$ & $76 \%$ & $83 \%$ & $69 \%$ \\
\hline & $\begin{array}{l}\text { Aprendo em treinamentos, tanto } \\
\text { presenciais quanto a distância }\end{array}$ & $69 \%$ & $64 \%$ & $75 \%$ \\
\hline & $\begin{array}{l}\text { Prefiro aprender por meio de } \\
\text { recursos tecnológicos e meios de } \\
\text { comunicação, como ensino a } \\
\text { distância e treinamentos online } \\
\end{array}$ & $25 \%$ & $22 \%$ & $28 \%$ \\
\hline & Reuniões favorecem a aprendizagem & $53 \%$ & $56 \%$ & $50 \%$ \\
\hline & $\begin{array}{l}\text { Aprendo quando leio ou assisto a um } \\
\text { vídeo }\end{array}$ & $92 \%$ & $94 \%$ & $89 \%$ \\
\hline & $\begin{array}{l}\text { Após o treinamento presencial, } \\
\text { aplico o conhecimento adquirido em } \\
\text { meu dia a dia }\end{array}$ & $79 \%$ & $69 \%$ & $89 \%$ \\
\hline & $\begin{array}{l}\text { Aprendo melhor em cursos a } \\
\text { distância quando comparado aos } \\
\text { cursos presenciais }\end{array}$ & $11 \%$ & $11 \%$ & $11 \%$ \\
\hline & $\begin{array}{l}\text { Prefiro aprender através dos meios } \\
\text { convencionais, como palestras e } \\
\text { atividades presenciais, que envolvam } \\
\text { menor uso de novas tecnologias }\end{array}$ & $54 \%$ & $50 \%$ & $58 \%$ \\
\hline INFORMAL & $\begin{array}{l}\text { Prefiro aprender por meio de } \\
\text { atividades independentes, que } \\
\text { possam ser realizadas } \\
\text { individualmente e no meu próprio } \\
\text { ritmo, ao invés do trabalho em } \\
\text { equipe }\end{array}$ & $22 \%$ & $25 \%$ & $19 \%$ \\
\hline
\end{tabular}

Revista de Gestão e Secretariado - GeSec, São Paulo, v. 5, n. 2, p 72-96, mai./ago. 2014. 


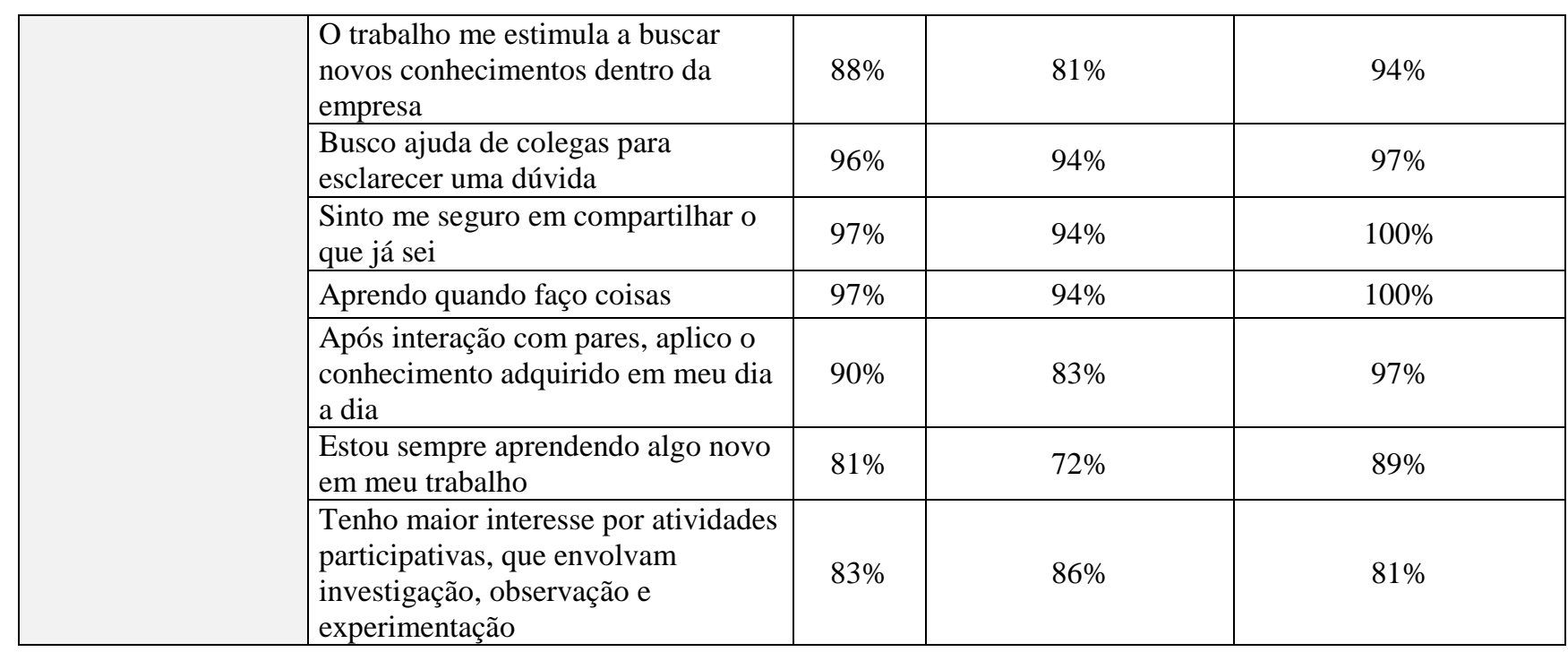

Fonte: elaborado pelos autores com dados da pesquisa.

Os administradores e não administradores apresentaram maior preferência em processos informais de aprendizagem aumentando a relevância das relações interpessoais. Havendo concordância geral de $97 \%$ da amostra ao afirmar que se sentem seguros em compartilhar conhecimento e existindo a concordância de $96 \%$ ao admitir a prática de buscar ajuda dos colegas para esclarecimento de dúvidas. Os respondentes demonstraram essa preferência nos processos espontâneos, não institucionalizados, de tentativa e erro, imitação, autodidatismo e busca de ajuda interpessoal abordados por Coelho, Borges e Andrade (2008).

Assim como a concordância de $90 \%$ da amostra em relação à percepção de que conseguem aplicar em seu dia a dia o conhecimento adquirido nas interações com os pares, reforça a predileção pela aprendizagem informal que ocorre quando há algum grau de consciência de que a pessoa está aprendendo, conforme conceituado por Antonello (2006). No entanto, embora haja maior preferência pela aprendizagem informal para ambos os grupos de gestores, existiram diferenças obtidas nos percentuais de concordância, que podem ser confirmadas pelo resultado do teste Anova da Tabela 7, onde o valor-P abaixo de 0,5 indica tal fato.

Revista de Gestão e Secretariado - GeSec, São Paulo, v. 5, n. 2, p 72-96, mai./ago. 2014. 
Tabela 7 - Resultados da Anova para a diferença entre aprendizagem informal de gestores formados em administração e outros cursos

\begin{tabular}{|l|c|c|c|c|c|c|}
\hline Fonte da variação & $\boldsymbol{S Q}$ & $\boldsymbol{g l}$ & $\boldsymbol{M Q}$ & $\boldsymbol{F}$ & valor-P & $\boldsymbol{F}$ crítico \\
\hline Entre grupos & 0,347 & 1 & 0,3472 & 0,776 & 0,3813 & 3,979 \\
\hline Dentro dos grupos & 31,306 & 70 & 0,4472 & & & \\
\hline Total & 31,653 & 71 & & & & \\
\hline
\end{tabular}

Fonte: elaborado pelos autores com dados da pesquisa.

Mesmo considerando a baixa preferência por metodologias formais de aprendizagem, foi possível identificar que, na análise geral, 92\% dos respondentes concordaram que aprendem enquanto leem ou assistem a vídeos e 79\% concordaram que após treinamentos presenciais, aplicam o conhecimento adquirido no dia a dia. Estas são evidências que demonstram a consciência de habilidades desenvolvidas após processos técnicos de transmissão de conhecimento e consonância com o resultado obtido na análise do índice de Kolb (Observação Reflexiva).

\subsection{ANÁlISES DAS VARIÁVEIS CONTEXTUAIS COMO INFLUÊNCIA DA APRENDIZAGEM DOS GESTORES}

Para a análise das variáveis contextuais foram utilizados os dados da Tabela 8 , resultantes de estatísticas descritivas das respostas dos gestores. Identificou-se que na variável cultura, apesar de os gestores afirmarem perceber que têm oportunidades para aprender e crescer no trabalho, apenas 69\% deles (sendo 67\% dos administradores e 72\% dos não administradores) percebe receber apoio e incentivo para aplicar os novos conhecimentos adquiridos. Esta divergência de resultados entre oportunidade de aprendizagem e aplicação dos conhecimentos pode ser um indício de que há desalinhamento entre o objetivo da empresa com a realização dos treinamentos e programas de treinamento e a real necessidade de cada uma das áreas (que recebe o treinamento).

Revista de Gestão e Secretariado - GeSec, São Paulo, v. 5, n. 2, p 72-96, mai./ago. 2014. 
Tabela 8 - Variáveis contextuais

\begin{tabular}{|c|c|c|c|c|}
\hline VARIÁVEL & PERGUNTA & GERAL & ADM & NÃO ADM \\
\hline \multirow{5}{*}{ Cultura } & Tenho oportunidades para aprender e crescer no trabalho & $99 \%$ & $97 \%$ & $100 \%$ \\
\hline & $\begin{array}{l}\text { Sinto-me estimulado a buscar novos conhecimentos fora da } \\
\text { empresa }\end{array}$ & $79 \%$ & $69 \%$ & $89 \%$ \\
\hline & $\begin{array}{l}\text { Recebo apoio e incentivo da empresa para aplicar novos } \\
\text { conhecimentos. }\end{array}$ & $69 \%$ & $67 \%$ & $72 \%$ \\
\hline & $\begin{array}{l}\text { Os valores básicos da organização onde trabalho incluem a } \\
\text { aprendizagem como a chave para a melhoria }\end{array}$ & $76 \%$ & $72 \%$ & $81 \%$ \\
\hline & Preocupo-me com o respeito à diversidade e questões sociais. & $88 \%$ & $89 \%$ & $86 \%$ \\
\hline \multirow{2}{*}{$\begin{array}{c}\text { Normas e } \\
\text { Procedimentos }\end{array}$} & $\begin{array}{l}\text { Tenho consciência do papel que desempenho no meu trabalho e } \\
\text { procuro defender minha opinião }\end{array}$ & $97 \%$ & $97 \%$ & $97 \%$ \\
\hline & $\begin{array}{l}\text { Sou conservador e respeito as posições hierárquicas, as tradições, } \\
\text { as leis e as regras diversas existentes na minha empresa }\end{array}$ & $51 \%$ & $56 \%$ & $47 \%$ \\
\hline \multirow{3}{*}{$\begin{array}{l}\text { Econômico e } \\
\text { Tecnológico }\end{array}$} & Valorizo o equilíbrio entre minha vida pessoal e profissional & $88 \%$ & $86 \%$ & $89 \%$ \\
\hline & $\begin{array}{l}\text { Sinto vontade de permanecer no meu trabalho se vislumbro } \\
\text { oportunidades de crescimento na carreira e quando recebo } \\
\text { incentivos monetários }\end{array}$ & $89 \%$ & $89 \%$ & $89 \%$ \\
\hline & Valorizo a criatividade e a inovação & $94 \%$ & $89 \%$ & $89 \%$ \\
\hline \multirow{3}{*}{ Experiência } & $\begin{array}{l}\text { Acredito que seja importante aprender com cada uma de minhas } \\
\text { experiências no trabalho }\end{array}$ & $94 \%$ & $94 \%$ & $94 \%$ \\
\hline & $\begin{array}{l}\text { Aprendo quando realizo reflexão sobre as atitudes do meu dia a } \\
\text { dia }\end{array}$ & $94 \%$ & $94 \%$ & $94 \%$ \\
\hline & $\begin{array}{l}\text { Tenho facilidade para adquirir conhecimento a partir de uma vasta } \\
\text { gama de informações. }\end{array}$ & $88 \%$ & $81 \%$ & $94 \%$ \\
\hline \multirow{4}{*}{ Relacionamento } & Ter autonomia favorece minha aprendizagem & $90 \%$ & $81 \%$ & $100 \%$ \\
\hline & $\begin{array}{l}\text { Aprendo no trabalho, com a troca de experiências e ideias entre os } \\
\text { colaboradores }\end{array}$ & $96 \%$ & $92 \%$ & $100 \%$ \\
\hline & $\begin{array}{l}\text { Convidamos pessoas de fora da nossa equipe para apresentar } \\
\text { informações ou debater conosco assuntos de interesse }\end{array}$ & $63 \%$ & $58 \%$ & $67 \%$ \\
\hline & $\begin{array}{l}\text { Sinto-me motivado quando recebo reconhecimento pelo trabalho } \\
\text { que desenvolvo }\end{array}$ & $99 \%$ & $97 \%$ & $100 \%$ \\
\hline
\end{tabular}

Nota: Adm $=$ Gestores formados em administração. Não Adm = Gestores com outras formações .

Fonte: Elaborado pelos autores com dados da pesquisa.

Observou-se também que considerando a motivação de busca por conhecimento, os não administradores se manifestam mais estimulados a adquiri-lo fora da empresa do que os gestores formados em administração, o que indicou uma possível dependência destes pela organização na

Revista de Gestão e Secretariado - GeSec, São Paulo, v. 5, n. 2, p 72-96, mai./ago. 2014. 
busca de novos conhecimentos. Reforçando a afirmação de Silva (2008) que a cultura pode interferir na aprendizagem à medida que o indivíduo reluta em sair da zona de conforto e a abandonar seus modelos mentais.

Para a variável "normas e procedimentos", os gestores com ambas as formações mostraramse conscientes em relação ao seu papel no trabalho, porém revelaram-se poucos conservadores, o que pode indicar uma facilidade dos gestores como um todo em lidar com mudanças, uma vez que as normas e os procedimentos abrangem um sistema de valores que auxiliam os indivíduos a entenderem situações práticas e a estabelecer uma conduta social aceitável (Silva, 2008).

As afirmativas em relação à variável econômica e tecnológica exibiram alta concordância entre os dois grupos da amostra, e no caso da afirmativa do equilíbrio entre vida pessoal e profissional, no geral $88 \%$ dos respondentes concordaram, o que demonstra a grande percepção de que os dois aspectos não interagem entre si, ou seja, os aspectos da vida pessoal não interferem na vida profissional. Em consonância a este resultado e reafirmando a consciência dos gestores do seu papel no trabalho, é evidente a afirmação de Antonello (2011), de que a aprendizagem é um fenômeno ligado ao ser humano que possibilita desempenhar seus diversos papéis no ambiente onde vive, transformando seu conhecimento e revendo a si mesmo por meio das experiências.

Em relação à variável experiência, as duas primeiras afirmativas apresentaram resultados idênticos nos dois grupos. Dos respondentes, 94\% concordaram que é importante aprender com cada uma das experiências no trabalho e que aprendem quando fazem uma reflexão sobre as atitudes do dia a dia. Esta elevada identificação demonstrou preferência na aprendizagem a partir da experimentação em toda a amostra. Em consonância a esses resultados, segundo Silva, (2008) o processo de aprendizagem ocorre quando as experiências vivenciadas levam o individuo a fazer associações com seus pressupostos.

Quanto ao relacionamento, verifica-se que $92 \%$ dos administradores e $100 \%$ dos não administradores afirmam que aprendem no trabalho, com a troca de experiências e ideias entre os colaboradores, fundamental para aprendizagem, conforme Silva (2008).

Tabela 9 - Recorte das correlações para administradores e não administradores

\begin{tabular}{|l|c|c|c|c|}
\hline & CULTURA & EXPERIÊNCIA & CULTURA & INFORMAL \\
\hline Administração & - & & & \\
\hline Relacionamento & 0,38 & 0,73 & & \\
\hline Informal & 0,70 & 0,43 & & \\
\hline Não administração & - & - & & \\
\hline Informal & $-0,09$ & 0,12 & 0,63 & 1 \\
\hline
\end{tabular}

Fonte: elaborado pelos autores com dados da pesquisa.

Revista de Gestão e Secretariado - GeSec, São Paulo, v. 5, n. 2, p 72-96, mai./ago. 2014. 
Dessa forma, todas as variáveis referidas não agem isoladamente, pois todo o sistema está integrado e qualquer mudança em uma delas gera mudanças nas demais.

Pela Tabela 9, observa-se que há correlação entre o relacionamento interpessoal e a experiência dos indivíduos, condizente com os resultados sobre o estilo de aprendizagem predominante para os gestores formados em administração, a acomodação. Outro aspecto a ser destacado é a correlação entre a aprendizagem informal e a cultura organizacional. Ou seja, entende-se que a aprendizagem se torna mais efetiva quando o ambiente da empresa é propício às trocas de experiências e ideias entre os colaboradores, por meio principalmente de ações não estruturadas pela organização.

\section{CONSIDERAÇÕES FINAIS}

Este artigo apresentou os principais resultados do estudo cujo objetivo foi analisar o processo de aprendizagem de gerentes e identificar possíveis diferenças entre gestores com diferentes formações (administradores versus não administradores). Nos resultados apresentados, verifica-se a relevante diferença na aprendizagem dos gestores administradores e não administradores. Evidenciando que suas respectivas formações acadêmicas lhe proporcionam visões diferentes para as tomadas de decisões, em que o primeiro busca aplicar sua aprendizagem na prática e a se relacionar com as pessoas, já o segundo visa o raciocínio lógico e impessoal e está mais voltado para os símbolos.

Verificou-se que o grupo total de respondentes constituiu-se de modo geral por gestores com o perfil de "observação reflexiva", ou seja, que tendem a refletir mais racionalmente antes da tomada de decisão e, por isso, rejeitam a subjetividade no processo de aprendizagem. Isto pressupõe que a atividade precisa ser lógica e fazer sentido a sua percepção de utilidade. É possível afirmar que, a partir dos resultados do presente estudo, o estilo de aprendizagem predominante destes profissionais os leva a preferir trabalhar em grupo e utilizar a imaginação para resolver problemas e refletir com base em suas experiências antes da tomada decisões, o que não os impedem de se adaptar facilmente a novas funções e desafios.

O resultado das variáveis contextuais permitiu identificar que os respondentes possuem um perfil de profissionais poucos conservadores, habilidosos em lidar com mudanças, o que pode

Revista de Gestão e Secretariado - GeSec, São Paulo, v. 5, n. 2, p 72-96, mai./ago. 2014. 
ser até mesmo uma consequência do exercício no papel de líder. Também foi possível observar que há preferência na aprendizagem a partir da experimentação em toda a amostra.

Como uma das contribuições do estudo, a relação entre a aprendizagem, experiência e o relacionamento foram os principais indicativos de que o gestor apresenta mais interesse no aprendizado quando se relaciona com outras pessoas que o leva a uma experiência prática daquele conhecimento, gerando por fim a percepção de maior aprendizagem. O que corrobora com a preferência apresentada pelos gestores em processos informais de aprendizagem, aumentando a relevância das relações interpessoais. Vale ressaltar que a referida preferência existe ainda que os respondentes tenham consciência de que métodos formais de aprendizagem também o possibilitam desenvolver habilidades e aplicar o conhecimento adquirido.

\subsection{LIMITAÇÕES E PESQUISA FUTURA}

O principal fator limitador do estudo foi o tamanho e a caracterização da amostra como não probabilística, visto que os resultados obtidos não podem ser generalizados para a população-alvo. Ainda assim, o presente estudo contribui para uma maior compreensão do processo da aprendizagem dos gerentes e seu contexto fomentador a fim de que houvesse a possibilidade de fundamentar a seleção e implantação das ações de treinamento e desenvolvimento considerando a formação destes líderes.

Outra limitação da pesquisa foi o fato de os gestores apresentarem formações em diferentes áreas, além da administração. Ou seja, talvez os resultados fossem diferentes se houvesse uma comparação entre administradores e engenheiros, por exemplo.

Sugere-se que novos estudos sejam feitos ampliando a amostra para que se obtenha maior embasamento nas inferências. Estudos que analisem também a influência de cada um dos fatores contextuais na preferência pela aprendizagem formal ou informal podem oferecer contribuições importantes para a área. Por fim, por meio de uma abordagem qualitativa, identificar no desempenho dos gestores novos comportamentos que comprovem a efetividade do aprendizado pode ser a base informacional que viabiliza a avaliação da efetividade dos processos de aprendizagem instituídos e se estes são alinhados com as preferências de cada indivíduo.

Dessa maneira, a partir de pesquisas empíricas sobre aprendizagem gerencial, será possível contribuir para a área acadêmica do conhecimento, bem como evidenciar para as organizações a necessidade de investimento em novas estratégias de aprendizagem no contexto do trabalho.

Revista de Gestão e Secretariado - GeSec, São Paulo, v. 5, n. 2, p 72-96, mai./ago. 2014. 


\section{REFERÊNCIAS}

Antonello, C. (2005). A metamorfose da aprendizagem organizacional: uma revisão crítica. In: Ruas, R.; Antonello, C. \& Boff, L. (orgs.). Aprendizagem organizacional e competências. Porto Alegre: Bookman.

. (2006). Aprendizagem na ação revisitada e sua relação com a noção de competência. Comportamento organizacional e gestão, vol.1, pp. 17-37.

. (2011). Saberes no singular? Em discussão a falta fronteira entre aprendizagem formal e informal. In: Antonello, C. \& Godoy, A. (eds.) Aprendizagem organizacional no Brasil. Porto Alegre: Artmed.

Antonello, C. \& Azevedo, D. (2011). Aprendizagem organizacional explorando o terreno das teorias culturais e das teorias baseadas em práticas. In: Antonello, C. \& Godoy, A. (eds.) Aprendizagem organizacional no Brasil. Porto Alegre: Artmed.

Babbie, E. (2005). Métodos de pesquisas de survey. Belo Horizonte, Minas Gerais: Editora UFMG.

Batista, G. \& Silva, M. (2008). Estilo de Aprendizagem Kolb, Cadernos da Fucamp, vol. 7, n.7.

Bido, D., Godoy, A., Ferreira, J., Kenski, J. \& Scartezini, V. (2011). Examinando a relação entre aprendizagem individual, grupal e organizacional em uma instituição financeira. Revista Eletrônica de Administração, Rio Grande do Sul, vol. 17, n. 1, pp. 58-85.

Coelho Junior, F. A. \& Borges-Andrade, E. J. (2008). Uso do conceito de aprendizagem em estudos relacionados ao trabalho e organizações. In: Paidéia, Ribeirão Preto, volume 18, número 40, pp. 221-234.

D’Amelio, M. (2007). Aprendizagem de competências gerenciais: um estudo com gestores de diferentes formações. Dissertação (Mestrado em Administração de Empresas), Universidade Presbiteriana Mackenzie, São Paulo.

(2011). Gerentes de diferentes formações e suas trajetórias de aprendizagem. In: Antonello, C.; Godoy, A. (orgs.) Aprendizagem organizacional no Brasil. Porto Alegre: Bookman.

Dantas, L. (2011). Aplicação do teste de Kolb na análise dos estilos de aprendizagem em ingressantes do Curso de Ciências Contábeis. Educação e formação profissional. Sergipe: UFS.

Revista de Gestão e Secretariado - GeSec, São Paulo, v. 5, n. 2, p 72-96, mai./ago. 2014. 
Easterby-Smith, M; Burgoyne, J. \& Araújo, L. (2001). Aprendizagem organizacional e organização de aprendizagem: desenvolvimento na teoria e na prática. São Paulo: Editora Atlas.

Estivalete, V.; Lobler, M. \& Pedrozo, E. (2006). Repensando o processo de aprendizagem organizacional no agronegócio: um estudo de caso realizado numa cooperativa destaque em qualidade no RS. Revista de Administração Contemporânea, vol.10, n. 2, pp. 157-178.

Fleury, M. \& Fleury, A. (2001). Construindo o conceito de competência. Revista de Administração Contemporânea, edição especial, pp. 183-196.

Fleury, M. \& Oliveira Jr, M. (2002). Aprendizagem e gestão do conhecimento. In: Fleury, M. (org). As pessoas na organização. São Paulo: Editora Gente.

Godoy, A. \& Antonello, C. (2009). Uma agenda brasileira para estudos em aprendizagem organizacional. Revista de Administração de Empresas. São Paulo. vol. 49, n. 3 pp. 266-281.

Hair, J. (2005). Fundamentos de métodos de pesquisa em administração. Porto Alegre: Bookman.

Kolb, D. (1984). Experiential learning: experience as the source of learning and development. New Jersey: Prentice Hall.

Leite, I. (2011) O aprendizado da função gerencial por meio da experiência. In: Antonello, C.; Godoy, A. (orgs.) Aprendizagem organizacional no Brasil. Porto Alegre: Bookman.

Leite, I.; Godoy, A. \& Antonello, C. (2003). aprendizado da função gerencial: os gerentes como atores e autores do seu processo de desenvolvimento. São Paulo: Universidade Presbiteriana Mackenzie.

Malhotra, N. (2011). Pesquisa de marketing: foco na decisão. (3a ed.). São Paulo: Pearson Prentice Hall.

Moraes, L.; Silva, M. \& Cunha, C. (2004). A aprendizagem gerencial: Teoria e pratica. Revista de Administração de Empresas- eletrônica, vol. 3, n. 1, jul/dez 2004.

Ruas, R.; Antonello, C. \& Boff, L. (2006). Os novos horizontes da gestão: aprendizagem organizacional e competências. Porto Alegre: Bookman.

Sampieri, R.; Collado, C.; Lucio, P. (2006). Metodologia de pesquisa (3a. ed.). São Paulo: McGraw-Hill.

Silva, A. (2008). O Contexto social da aprendizagem de gerentes. Revista de Administração Mackenzie, São Paulo, vol. 9, n. 6, pp. 26-52.

Revista de Gestão e Secretariado - GeSec, São Paulo, v. 5, n. 2, p 72-96, mai./ago. 2014. 